\title{
AREND, SILVIA MARIA F.; MOURA, ESMERALDA B. B. DE; SOSENSKI, SUSANA. \\ (ORGS.). INFÂNCIAS E JUVENTUDES NO \\ SÉCULO XX: HISTÓRIAS LATINO- \\ AMERICANAS. PONTA GROSSA: \\ TODAPALAVRA, 2018. 368P.
}

\author{
Chirley Beatriz da Silva Vieira* \\ Otoniel Rodrigues Silva*
}

O livro Infâncias e juventudes no século XX: histórias latinoamericanas apresenta os resultados de investigações realizadas por integrantes do Grupo de Trabalho História da Infância e da Juventude, filiado à Associação Nacional de História - ANPUH-Nacional, e por historiadores membros da Red de Estudios de Historia de las Infâncias en América Latina - REHIAL (https://www.aacademica.org/rehial), criada em 2018. A obra é produto de reflexões que demonstram como os processos sociais relativos à infância, adolescência e juventude (para além do âmbito da escola) têm adquirido uma maior importância na historiografia da América Latina. Essa importância está certamente associada ao fato de que problemas de diferentes ordens relativos a essa parte da população latina ainda são grandes desafios a governos e sociedades que compõem o continente. É importante observar ainda que o livro é composto por capítulos redigidos nos idiomas português e espanhol.

As três organizadoras da obra - Silvia Maria Fávero Arend, docente da Universidade do Estado de Santa Catarina, Esmeralda B. B. de Moura, da Universidade de São Paulo (USP), e Susana

\footnotetext{
* Mestre em Educação, pela Universidade do Estado de Santa Catarina (UDESC).

E-mail: schirleypsi@gmail.com.

* Doutorando em Educação, pela Universidade do Estado de Santa Catarina (UDESC).

E-mail: otonielifsc@gmail.com.
} 
Sosenski, que atua na Universidad Nacional Autónoma de México (UNAM) - têm produzido vários estudos na área das Ciências Humanas, especialmente no campo da História da Infância e da Juventude.

No prólogo do livro, a historiadora estadunidense Elena Jackson Albarrán destaca as inovações contidas nas reflexões realizadas pelos autores nos treze capítulos que compõem a obra, seja do ponto de vista das temáticas abordadas ou das opções teórico-metodológicas. A mencionada historiadora enfatiza ainda a gama de fontes documentais utilizadas pelos autores na escrita de suas narrativas, parte delas ainda inédita.

O livro está organizado em cinco partes. A primeira aborda a temática da família e é composta de quatro capítulos, iniciando pelo que foi escrito por Esmeralda B. B. de Moura, sob o título "Castigar com 'moderação e amor': a criança e o castigo na interlocução entre o direito, a educação e os princípios do catolicismo (Brasil: séculos XIX e XX)". A autora efetuou uma discussão sobre o tema do castigo físico aplicado às crianças enquanto uma forma de educação considerada eficaz pela Igreja Católica e pelo Estado brasileiro. $\mathrm{Na}$ construção da narrativa a historiadora analisou parte da legislação brasileira que trata do tema, a saber: o Código Criminal do Império de 1831, o Código Penal Republicano de 1890 e Código Civil de 1916.

O segundo capítulo é intitulado "A tutela de crianças na belle époque: justiça e relações de gênero (Porto Alegre/Brasil, início do século XX)", de autoria do historiador José Carlos da Silva Cardozo. $\mathrm{O}$ autor analisou a atuação dos representantes do Juízo de Órfãos da capital do Estado do Rio Grande do Sul tendo em vista os processos jurídicos de tutela de menores de idade. De maneira geral, o instituto jurídico da tutela era utilizado por operadores do Direito no início do período republicano em função da falta de condições econômicas dos pais para garantir o sustento de sua prole ou quando os genitores efetuavam práticas que as autoridades consideravam imorais. Além disso, o autor procurou identificar quais eram as exigências realizadas pelos operadores do Direito para que os pais pudessem reaver a guarda de filhos e filhas.

$\mathrm{O}$ capítulo três intitula-se "Assistência à infância e à maternidade na Primeira República: as experiências médicofilantrópicas de proteção materno infantil na cidade do Rio de 
Janeiro" e foi redigido pelo historiador Ismael Gonçalves Alves. O capítulo tem como foco as práticas de caráter higienista estabelecidas para mulheres e crianças pobres, principal público das instituições assistenciais da cidade do Rio de Janeiro no início do século XX. Com essas medidas, médicos e filantropos pretendiam que a maternidade e a infância atingissem níveis sanitários que contribuíssem para o aumento da população brasileira.

A primeira parte do livro finaliza com o capítulo de autoria da historiadora Silvia Maria Fávero Arend, intitulado "Três meninas brasileiras pobres: relações de trabalho sob uma perspectiva interseccional (1930-1990)". A autora, tendo em vista processos judiciais produzidos pelo Juizado de Menores da Comarca da Capital e de processos emitidos pela Justiça do Trabalho de Santa Catarina, descreveu a trajetória de vida de três meninas pobres que habitaram em Florianópolis nos anos de 1940 e de 1990. A autora procurou analisar, sob o enfoque teórico das relações de gênero e interseccionais, o porquê das jovens, que viveram em períodos distintos, terem sido obrigadas a labutar nos serviços domésticos desde a infância e não acessaram o saber escolar.

A segunda parte do livro é dividida em três capítulos que discutem a temática do consumo relacionado à infância e à juventude no Brasil e no México. O primeiro capítulo, de autoria da cientista social Alejandra Josiowicz, é intitulado "Una infancia moderna: consumo cultural, niñez y nuevos modelos familiares en Clarice Lispector". A autora aborda como a prole das famílias das camadas médias urbanas brasileiras nos anos de 1960 e 1970 ingressaram no mercado consumidor de bens de cunho cultural. $\mathrm{O}$ foco da análise da autora recai sobre a produção literária infantil, tendo em vista o caso da escritora Clarice Lispector, uma das autoras que mais vendeu livros para o público infantil no referido período no país.

O segundo capítulo dessa parte da obra intitula-se "El dia del niño en México: del festejo del trabajo a la fiesta del consumo (19201940)" e foi redigido pela historiadora Susana Sosenski. A autora descreveu o processo que deu origem à celebração do "Dia da Criança" no México, assim como às transformações de cunho sociocultural por que passou essa efeméride entre as décadas de 1920 e 1940. Em sua análise a historiadora identificou os diferentes 
significados atribuídos à festa em função de um mercado consumidor infantojuvenil que estava sendo edificado naquele período no país.

O terceiro e último capítulo desta parte foi redigido pelo historiador Cristiano José Pereira, sob o título "À procura da motocicleta perdida: juventude no trânsito brasileiro e consumo (1974-2000)". A narrativa tem como foco as representações sociais veiculadas na revista Duas Rodas Motociclismo acerca dos jovens do sexo masculino das camadas médias urbanas brasileiras que almejavam possuir uma motocicleta para ser utilizada para o lazer e/ou no âmbito do trabalho.

A terceira parte do livro aborda a temática das ditaduras latino-americanas e constitui-se de dois capítulos. O primeiro foi escrito pela psicóloga Patricia Castillo, sob o título "Cultura material, memoria y microhistoria de la infancia". O texto tem como tema os debates de caráter historiográfico, teórico e metodológico especialmente sobre a questão do protagonismo infantojuvenil efetuados pela autora no processo de construção de exposições museológicas acerca da ditadura militar que se impôs ao Chile entre os anos 1973 e 1989.

O segundo capítulo desta parte da obra intitula-se “'Pibes' en el centro de la escena: infancia, sensibilidades y lucha política en la Argentina de los setenta", de autoria da historiadora Isabella Cosse. A autora, a partir de matérias jornalísticas publicadas no periódico Notícias, procurou analisar quais foram as representações sociais enunciadas acerca de crianças e adolescentes de ambos os sexos pelo grupo político de esquerda denominado de Monteneros, com ampla atuação na década de 1970 na sociedade argentina.

A quarta e última parte da obra aborda o tema da construção jurídica da menoridade em dois capítulos. O primeiro capítulo, intitulado "Semanas de estudos do problema de menores: debates acerca do atendimento à infância e à juventude (São Paulo, 19301950)", foi redigido pelo historiador Ailton José Morelli. O autor analisou os debates promovidos por operadores do Direito do estado de São Paulo nos eventos "Semana de Estudos do Problema de Menores", realizados entre os anos 1948 e 1951, com foco nos então chamados "menores" abandonados, delinquentes e trabalhadores. A partir desses debates, novas políticas públicas foram formuladas para 
essa população infantojuvenil já não mais somente sob um enfoque salvacionista.

O segundo capítulo, escrito por Humberto Miranda, intitulase "Em busca da família ideal: a Funabem, o abandono de crianças e a política de 'manutenção do menor no lar' (Pernambuco, 1960-1970)". $\mathrm{O}$ autor, a partir de um conjunto de fontes documentais - relatórios sociais, matérias jornalísticas e impressos de diferentes tipos produzidas pela equipe técnica da Fundação do Bem-Estar do Menor (FUNABEM) do estado de Pernambuco (formada por profissionais das áreas da Pedagogia, Psicologia, Serviço Social e do Direito), buscou analisar o discurso enunciado acerca das famílias das crianças, adolescentes e jovens que estavam abrigados em instituições daquele Estado da federação durante a ditadura militar.

A quinta e última parte da obra discute a temática do trabalho em dois capítulos. O primeiro intitula-se "O trabalho infantil em debate na América Latina: primeira metade do século XX" e é de autoria do historiador Eduardo Silveira Netto Nunes. O autor, tendo em vista os Anais dos Congressos Pan-americanos da Criança ocorridos entre os anos 1916 e 1948 e as legislações de caráter nacional então vigentes, analisou os significados atribuídos à temática do trabalho infantojuvenil nos diferentes países, bem como o labor dos considerados menores de idade foi regulamentado por nações latino-americanos na primeira metade do século XX.

O último capítulo do livro é de autoria do historiador Antero Maximiliano Dias dos Reis e tem como título "Impactos e dilemas do ECA junto à justiça do trabalho: a erradicação do trabalho infantojuvenil na venda ambulante de jornais (Florianópolis, década de 1990)". O autor analisou as modificações ocorridas nas relações de trabalho vigentes entre as empresas jornalísticas da capital do Estado de Santa Catarina e os meninos que vendiam jornais após a implementação do Estatuto da Criança e do Adolescente na década de 1990. O capítulo foi redigido a partir de informações contidas nos processos produzidos no âmbito da Justiça do Trabalho (Tribunal Regional do Trabalho da $12^{\mathrm{a}}$ Região).

O livro constitui-se em uma excelente contribuição para os estudos da área da História da Infância e Juventude na América Latina. Além disso, poderá servir para que profissionais que atuam no campo da infância e da juventude - pedagogos, assistentes sociais, 
operadores do Direito, psicólogos, etc - possam adensar os seus conhecimentos sobre a temática, fazendo com que a historiografia cumpra um dos seus papeis mais relevantes no âmbito social.

RECEBIDO EM: 26/02/2019 APROVADO EM: 18/06/2019 